\title{
DEVELOPING COUNTRIES
}

\section{The rice-based diet in Bangladesh in the context of food and nutrition security}

\author{
By Inge Tetens, Shakuntala Haraksingh Thilsted, \\ Nurul Hoque Choudhury and Nazmul Hassan
}

\begin{abstract}
Bangladesh is experiencing a situation with both food and nutrition insecurity. Bangladesh has developed a national plan of action within the food and nutrition area following the international plans of action. Examples of different ongoing programmes and projects related to food and nutrition security are described, including a more detailed description of the authors's own research activities. Research components pertinent to the Bangladesh rice-based diet comprise dietary surveys in rural Bangladesh in villages with different production patterns, perception studies of the commonly consumed foods, studies of the nutritional quality of the most important foods (rice, fish and vegetables) and bioavailability studies of starch from rice and calcium from small indigenous fish. Results are presented along with needs for future research.
\end{abstract}

\section{Food and nutrition situation}

Rice is the staple food of Bangladesh, a South-Asian country with the world highest population density. Parboiled rice is eaten at least twice a day along with small amounts of vegetables and fish. National food surveys conducted in rural Bangladesh in 1981/82 showed that the average food intake was $765 \mathrm{~g}$ raw food per person, of which $60 \%$ was rice, $30 \%$ was vegetables and around 6\% animal foods (1). These figures confirmed earlier data on food intake collected in rural areas in $1975 / 76$ and 1962/64. In terms of energy, rice contributes up to $86 \%$ of total energy intake in the rural population (1).

In Bangladesh, as in many other lowincome countries, a close relationship exists between local food production and

Inge Tetens ${ }^{1}$, Ass Prof, Shakuntala Haraksingh Thilsted $^{1}$, Ass Prof, Nurul Hoque Choudhury ${ }^{2}$, Chief Scientific officer and Head, Nazmul Hassan ${ }^{3}$, Prof.

Correspondence: Inge Tetens, Research Department of Human Nutrition. The Royal Veterinary and Agricultural University, Rolighedsvej 30, DK-1958 Frederiksberg, Denmark. E- mail: ite@kvl.dk

In the Bangladesh project, descried in the article, the following persons are also involved: Sunil Biswas ${ }^{2}$, Marianne Hansen ${ }^{1}$, Ole Hels ${ }^{1}$, Khandaker Aminul Kabir ${ }^{2}$, Abu Halal Mohammed Kohinoo ${ }^{4}$ Nazrul Islam Khan ${ }^{3}$, Katja Kongsbak ${ }^{1}$, Hanne Nygaard Larsen ${ }^{1}$, Torben Larsen ${ }^{5}$, Nanna Roos ${ }^{1}$, Mohammed Abdul Wahab ${ }^{4}$

${ }^{1}$ Research Department of Human Nutrition, The Royal Veterinary and Agricultural University, Frederiksberg, Denmark.

${ }^{2}$ Grain Quality and Nutrition Division, Bangladesh Rice Research Institute, Gazipur, Bangladesh.

Institute of Nutrition and Food Science, Dhaka

University, Dhaka, Bangladesh.

${ }^{4}$ Department of Fisheries Management, Bangladesh Agricultural University, Mymensingh, Bangladesh.

Department of Animal Health and Welfare, Danish Institute of Agricultural Sciences, Research Centre Foulum, Denmark. food intake. During the period from 1975/ 76 to 1992/93 food grain production (predominantly rice) increased at an annual rate of $2.7 \%$ against a population growth rate of $2.1 \%(2)$. However, despite the increase in grain production and the adoption of several other measures (e.g. private imports of foods), Bangladesh is still experiencing food deficits. Seasonal and regional variations in production and income generation opportunities result in substantial fluctuations in food consumption.

Household expenditure surveys have shown that about half of the population of 120 million people live below the absolute poverty line (here defined by the minimum energy intake of $8.9 \mathrm{MJ} / \mathrm{d}$ ) while approximately one-fourth of the population consume less than $7.6 \mathrm{MJ} / \mathrm{d}$, thus categorized as the "hard-core"poor (3). At present, the average per capita energy intake is estimated to be around $80 \%$ of the level recommended by FAO (2). Poverty, closely associated with land ownership, income and lack of access to food, plays a crucial role in the food and nutrition insecurity experienced by Bangladesh (2).

Mortality, morbidity and anthropometric measurements are often used as outcome indicators of nutritional status. A few selected indicators are given in Table 1 . While protein-energy malnutrition (PEM) is the main nutritional problem, iron deficiency anaemia, vitamin A deficiency and iodine deficiency disorders are also widely prevalent. More than $70 \%$ of the women and children suffer from iron deficiency anaemia, more than 30,000 children become blind each year due to vitamin A deficiency (4) and about $50 \%$ of children between 6 and 11 develop palpable or visible goitre due to low intake of iodine (5). Lack of food is not the only cause of malnutrition. Inadequate care, especially for children, pregnant and lactating women and lack of access to health services, safe water and sanitation are important contributing factors to food and nutrition insecurity.

In spite of an increase in total food production and a general improvement in public health over the last decade, Bangladesh is in a situation with both food and nutrition insecurity.

\section{Global food and nutrition plan of actions}

In December 1992, The International Conference on Nutrition (ICN) was held in Rome under the auspices of the FAO and WHO. The ICN became a landmark for the global nutrition scene, setting nutrition high on the agenda for future actions to be adopted at international, regional, national and household levels. At the ICN, consensus was obtained that the cornerstones of nutrition security comprise the three areas: Food, Health and Care.

A Plan of Action on Nutrition was formulated as action oriented themes and was unanimously approved by the representatives of more than 150 countries (Table 2 ).

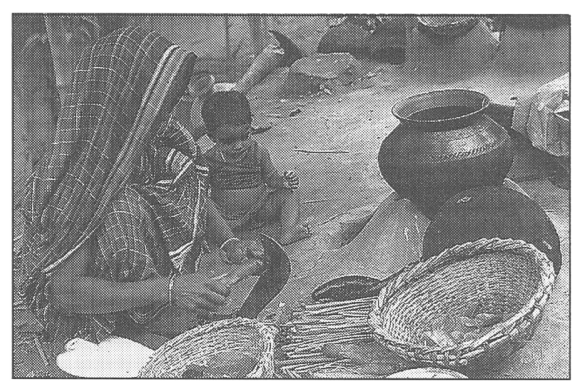

Woman preparing the next meal.

Photo: Inge Tetens 
Table 1. Selected indicators of nutritional status in Bangladesh as compared to Denmark.

$$
\text { Bangladesh Denmark }
$$

\begin{tabular}{|c|c|c|c|}
\hline \multicolumn{2}{|l|}{ Under-5 mortality rate per 1000 live births } & 112 & 6 \\
\hline Life expectancy at birth & yrs & 57 & 75 \\
\hline Infants with low birthweight ${ }^{1}$ & $\%$ & 51 & 6 \\
\hline Stunting ${ }^{2}$, prevalence among $<5$ yrs & $\%$ & 55 & - \\
\hline Underweight $^{3}$, prevalence among $<5$ yrs & $\%$ & 21 & - \\
\hline Wasting 4 , prevalence among $<5$ yrs & $\%$ & 18 & - \\
\hline
\end{tabular}

${ }^{1}$ Low birth weight: less than 2500 grams

2 Stunting: below minus 2 standard deviations (SD) from median height for age of reference population

3 Underweight: below minus 2 SD from median weight for age of reference population

${ }^{4}$ Wasting: below minus 2 SD from median weight for height of reference population

Source: UNICEF (5)

Table 2. Plan of Action on Nutrition adopted at the International Conference on Nutrition, 1992.

1. Incorporating nutritional objectives, considerations and components into development policies and programmes

2. Improving household food security

3. Protecting consumers through improved food quality and safety

4. Preventing and managing infectious diseases

5. Promoting breast feeding

6. Caring for the socio-economically deprived and nutritionally vulnerable

7. Preventing and controlling specific micronutrient deficiencies

8. Promoting appropriate diets and healthy lifestyles.

9. Assessing, analysing and monitoring nutrition situations

Source: (6)

Table 3. Plan of action adopted at the World Food Summit, 1996.

1. Achieve sustainable food security for all

2. Improve physical and economic access by all, at all times, to sufficient, nutritionally adequate and safe food and its effective utilization

3. Pursue participatory and sustainable food, agriculture, fisheries, forestry and rural development policies and practices at all levels

4. Ensure food, agricultural and overall trade policies to be conductive to fostering food security for all

5. Endeavour prevention and preparation for natural disasters and man-made emergencies and to meet transitory and emergency food requirements

6. Promote optimal allocation and use of public and private investments to foster human resources, sustainable food, agriculture, fisheries and forestry systems, and rural development, in all areas

7. Implement, monitor and follow-up the Plan of Action at all levels

Source: $(7$, modified $)$
A very important outcome of the ICN was that many countries have formulated their national nutrition plan of action.

In November 1996, The World Food Summit (WFS) was held by FAO in Rome with the participation of 186 countries. At the WFS, the need to tackle the problems of food insecurity together with malnutrition was emphasized. Following the definition "Food Security exists when all people, at all times, have physical and economic access to sufficient, safe and nutritious food to meet their dietary needs and food preferences for an active and healthy life", and taking into account the multidisciplinary nature of food and nutrition security, the WFS directed its focus through the Plan of Action towards ways of achieving sustainable food security for all as one of the prerequisites for nutrition security. The Plan of Action from the WFS was formulated in seven commitments which are summarized in Table 3. The Plan of Action calls for commitments at all levels and at the same time, calls for multidisciplinary actions.

\section{Actions in Bangladesh}

The government of the People's Republic of Bangladesh was represented at both the ICN and the WFS. Based on the plan of actions from these conferences the government has formulated its own National Nutrition Plan.

Numerous programmes and projects related to food and nutrition security are being carried out by both governmental and non-governmental organizations (NGO). Examples of governmental programmes include the "Health for All by 2000" programme, in which both preventive and curative health care facilities have been launched and expanded, including programmes on vitamin A capsule distribution, universal salt iodization, immunization, pre- and postnatal maternal care, prevention and cure of diarrhoea and respiratory infection. In addition, the World Bank is undertaking the "Bangladesh Integrated Nutrition Project" and the World Food Programme the "Vulnerable Group Development Programme". Examples of ongoing NGO programmes include credit operations by the Grameen Bank, the Bangladesh Rural Advancement Committee (BRAC) and several other NGOs, with the focus on providing credits and/or self-employment to women in homestead gardening, fisheries, poultry and non-farm activities. These include Helen Keller International (HKI) Home Gardening and Nutrition Education project, which is implemented with local NGOs, and the United Development Initiatives for Programmed Actions (UDDIPAN) Child Nutrition Project, being implemented with support from Save the Children (Red Barnet), Denmark.

\section{Own research activities}

The aim of our research activities in Bangladesh throughout the last five years has been to contribute to the provision of a solid basis for documenting the nutritional importance of commonly consumed foods. The results from our different research components will ensure a stronger basis for recommendations of nutrient and food intake as well as of a sustainable food production which can direct the policies and strategies within agriculture production to ensure better nutrition.

Through different research, training and capacity-building components, our efforts have concentrated on the aspects pertinent to the Bangladesh rice-based diet. Present research activities are described below:

\section{Food and nutrient intake in rural Bangladesh}

The aim of this research component was to describe the intake of food and nutrients in a rural setting by including two villages in Bangladesh with different agricultural production systems, taking into account seasonal and socio-economical factors. Dietary surveys were carried out in two rural locations, representing both an agriculturally traditional and a modern village, respectively. About 150 households in each village were drawn statistically to cover households belonging to different socio-economic groups. The households were visited during two seasons: the lean season (pre major rice harvest, October-November) and the peak season (post major rice harvest, FebruaryMarch), when the food intake of all individuals was weighed using the 24-hour weighing method. Anthropometric measurements were done on all individuals in both seasons and information on socio- 
Figure 1. Contribution from major food groups to average total daily food intake in two Bangladeshi villages with traditional (village 1: V1) and modern (village $2: \mathrm{V} 2$ ) rice production in the lean and the peak season.

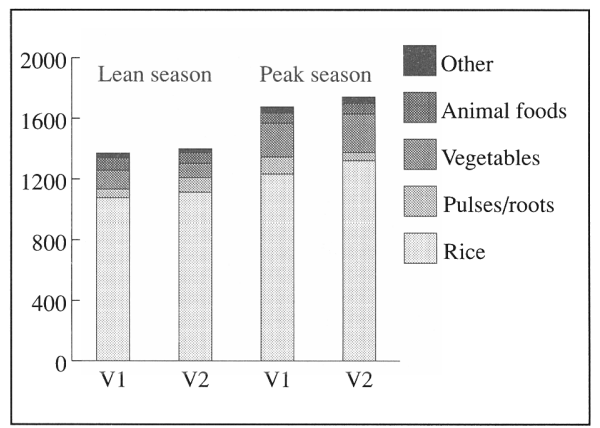

economic indices was obtained using predesigned and pre-tested questionnaires.

Some preliminary results from the survey on the contribution to the average total dietary intake from different food groups are presented in Figure 1. Rice plays by far the dominant role in the daily food supply, providing between $75 \%$ and $80 \%$ of daily intake when calculated on "as eaten" basis. Statistical analyses (repeated measures ANOVA) showed that differences in food intake were significant $(\mathrm{P}<0.05)$ between villages, seasons and socio-economic groups, while differences in rice intake were significant $(\mathrm{P}<0.01)$ between villages and seasons. These results will be published elsewhere (Tetens et al, unpublished).

The average intake of fish at household and village level was recorded and divided into intake of big and small fish. Ranking of fish species consumed by individuals and households was also carried out. The same procedure was followed with regard to vegetables, which were divided into green leafy and non-green leafy vegetables. In spite of the small contribution to the total food intake from fish (below 5\%) and from vegetables (between 7 and 15\%), fish and vegetables contribute important amounts of micronutrients to the diet (results not shown).

\section{Nutritional quality of rice}

The aim of this research component was to study the nutritional quality of rice with the emphasis on variations between varieties and effects of processing, especially parboiling. Several specific objectives were included:

1) to study total digestibility and rate of rice starch digestion;

2) to determine protein quality;

3) to measure the content of minerals and phytic acid.

The starch content and rate of starch

Figure 2. Starch digestion index (SDI) of selected non-parboiled (nPB) and parboiled (PB) modern rice varieties (mean \pm s.e.m.).

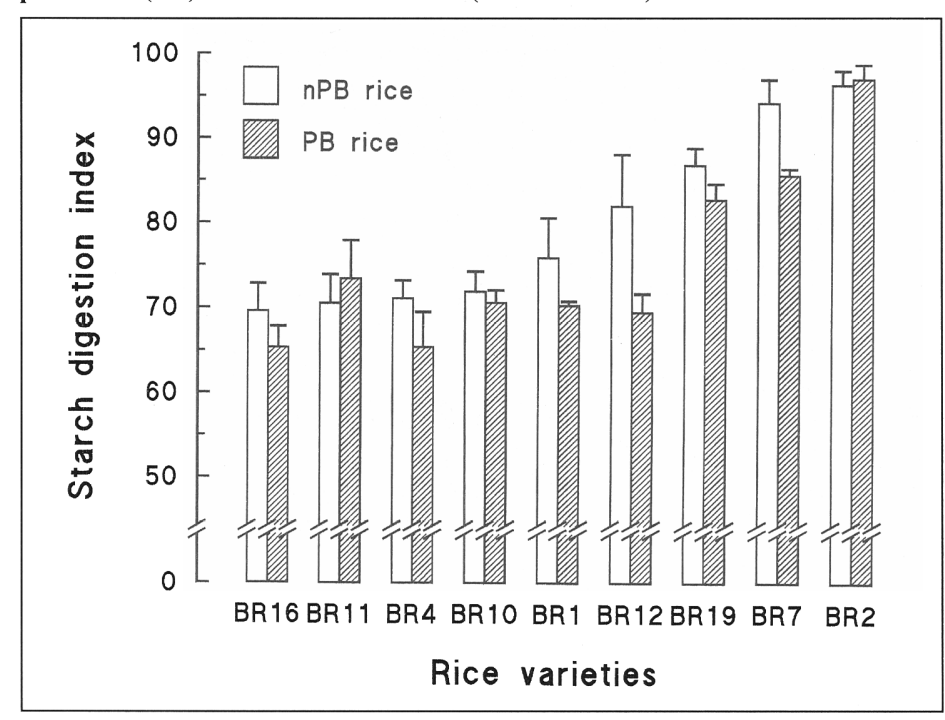

digestion were determined on selected modern high yielding varieties (HYV) rice samples using the in vitro method of Englyst et al. (8). Total starch (TS), rapidly digestible starch (RDS) and slowly digestible starch were determined and the starch digestion index (SDI) (calculated as: $\mathrm{SDI}=(\mathrm{RDS}) /(\mathrm{TS} \times 100))$ was used as a measure of the rate of starch digestion. The results of the SDI measurements of nine selected HYV rice samples prepared both as non-parboiled (nPB) and parboiled (PB) rice are shown in Figure 2. Parboiling significantly reduced the rate of starch digestion $(\mathrm{P}<0.0001)$. Results of chemical analyses and physical measurements revealed that the most significant determinants for the rate of starch digestion were the apparent amylose content, width and shape of the milled rice grain and the elongation ratio after cooking (9).

The rate of starch digestion and absorption from rice samples was measured as the glycaemic response to rice meals in non-insulin-dependent diabetics (NIDDM) in Denmark. The results showed that all investigated rice varieties were low-glycaemic as compared to white bread, and further that the degree of parboiling and amylose content are important determinants for the glycaemic response to cooked rice (Figure 3) (10). Comparative studies have been conducted in Bangladesh and the results are now being analysed.

Protein quality was determined in a range of modern and traditional Bangladeshi rice varieties by measurements of the contents of individual amino acids and determination of protein utilization in a rat model. The results showed that both protein quality and utilization varied considerably between varieties (11).

Mineral content was determined in se- lected HYV rice samples grown under similar conditions and milled to the same degree. The results showed that the range in contents of minerals may be twofold (12). These results are being verified in further studies, taking into consideration differences in cultivation practices and processing methods.

\section{Perception of rice, fish \\ and green leafy vegetables}

With the extensive changes in food production towards increased use of highyielding rice varieties in Bangladesh over the last two decades, little attention has been paid to the perceptions of the rural consumers on these modern varieties. Interviews were carried out with 17 females and 17 males selected randomly from the households included in the food consumption survey. It was found that the modern rice varieties were preferred because of their low price while the traditional rice varieties were preferred primarily because of "better taste". The modern rice varieties were regarded as most suitable for house servants/daily labourers and poor people, whereas the traditional rice varieties were regarded as best for special occasions, such as weddings and for certain population groups, such as children, the sick and the rich (13). This small study thus indicates that consumer preferences may be quite different from the preferences of the rice breeders and growers.

Studies on the perceptions of women on small indigenous fish species (SIS) and green leafy vegetables (GLV) were conducted in 150 households. The results suggest that rural women consider GLV to be a low-status food and they are not given to children, pregnant and lactating women 
Figure 3. Mean plasma glucose and insulin response areas in 12 NIDDM patients to two rice meals of $50 \mathrm{~g}$ available carbohydrates (mean \pm s.e.m.).

- high amylose rice, $O$ low amylose rice.

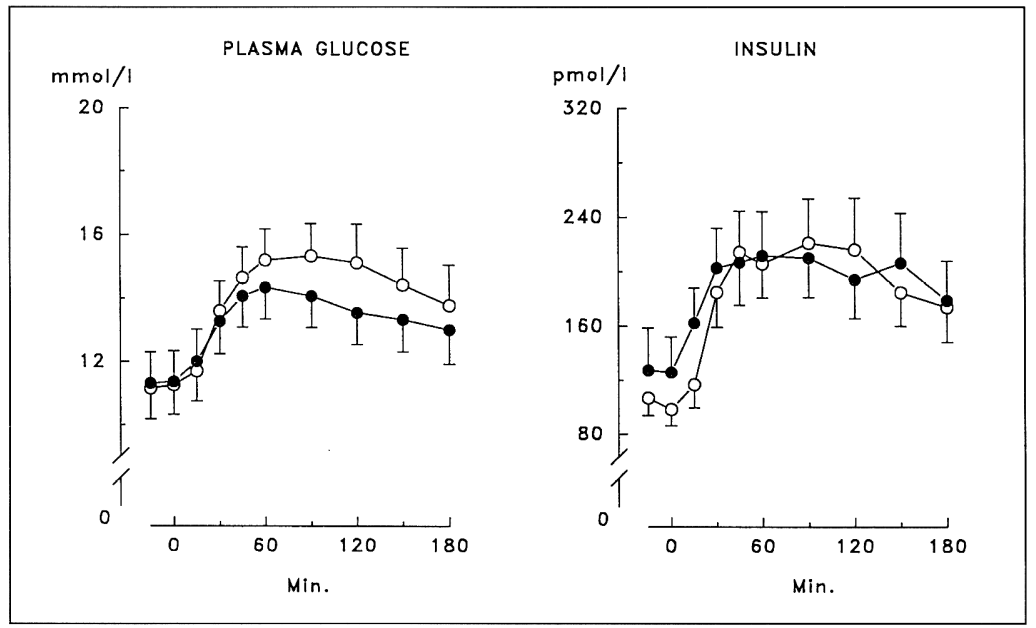

for fear that these foods may cause stomach problems. However, the women's perceptions on SIS were very positive and some species were considered as foods which give good health, good eyesight and blood (14).

\section{Nutritional quality - fish species}

The aim of this research component was to investigate the feasibility of the production of small indigenous fish (SIS) in polyculture with big fish in small seasonal ponds. Further aims were to determine the contribution of SIS to the total fish intake in different seasons and locations and to determine the contribution of SIS to nutrient intakes. The majority of fish eaten by the rural poor is the SIS, whereas the big and more expensive fish are consumed by households with more assets and by the urban population. Many SIS are less than $10 \mathrm{~cm}$ long and they are normally eaten

Table 4. Content of vitamin $A$ and calcium in small and big Bangladeshi fish species (per $100 \mathrm{~g}$ raw edible part).

\begin{tabular}{lrc}
\hline & \multicolumn{2}{c}{ Vitamin A Calcium } \\
Fish species & $\mu \mathrm{g}$ & $\mathrm{mg}$ \\
& & \\
\hline Small indigenous fish & & \\
Mola & 1960 & 1071 \\
(Amblypharyngodon mola) & & \\
$\begin{array}{l}\text { Dhela (Rohtee cotio) } \\
\text { Chanda (Chanda } \text { sp.) }\end{array}$ & 937 & 1260 \\
Puti (Puntius spp.) & 341 & 1162 \\
Big fish & 37 & 1059 \\
Hilsa (Hilsa ilisha) & & \\
Rui (Labeo rohita) & 69 & 126 \\
Silver carp & 27 & 317 \\
(Hypophtalmichthys molitrix) & & \\
& 17 & 268 \\
\end{tabular}

whole, with bones and organs. Analyses of SIS have shown that they contain high amounts of calcium, iron and zinc. Some species, like the popular mola (Amblypharyngodon mola) fish contain very high amounts of vitamin A (Table 4). Only $25 \mathrm{~g}$ of mola fish per day fulfil the recommended intake of vitamin A for a 4-6-year-old child (14).

The bioavailability of calcium from SIS was found to be comparable to that of skimmed milk in young growing rats (Larsen T et al., unpublished). These results have recently been confirmed in a human trial, using a radioisotope method. The fractional calcium absorption measured by the absorption of ${ }^{47} \mathrm{Ca}$ was $23.8 \%$ from the fish meal and $21.8 \%$ from milk meal, which was not significantly different $(\mathrm{p}=0.52)(15)$.

\section{Conclusions and further research}

Rice contributes such a large proportion of the rice-based diet of Bangladesh that it remains of utmost importance to optimize the nutritional quality of the rice varieties produced or introduced for production in the future. Fish, and especially small indigenous fish, together with vegetables with a high micronutrient density add very important micronutrients to the diet. Further studies on the contents of micronutrients in different fish and vegetable species and the bioavailability of these micronutrients are needed. Our studies will be pursued by studying rice, fish and vegetables individually and together in a whole diet. Field surveys along with production trials will continue, followed by in-depth intervention and laboratory studies in order to achieve our overall research aim.

\section{International network}

Our activities are closely linked to international projects conducted by three of the Consultative Group on International Agricultural Research (CGIAR) institutions within the area of food and nutrition security: International Food Policy Research Institute (IFPRI), International Centre for Living Aquatic Resources Management (ICLARM) and International Rice Research Institute (IRRI). The project has very close ties with the Mymensingh Agriculture Extension Project (MAEP), funded by Danida (Danish International Development Assistance). The results from the research on the small fish have been used by several projects within their rural development programmes.

\section{Acknowledgements}

This work is supported by Danida through a postdoctoral and PhD grants from RUF (Research Council for Research in Developing Countries) and through ENRECA (The Bilateral Programme for Enhancement of Research Capacity in Developing Countries). BSc, MSc and PhD students from Bangladesh and Denmark have contributed to the work accomplished.

\section{References}

1. Ahmed K and Hassan N: Nutrition survey of rural Bangladesh 1981-82. Institute of Nutrition and Food Science, Dhaka, 1983.

2. Ministry of Agriculture: Bangladesh Food and Agriculture. Country. Position Paper, World Food Summit, 13-17 Nov, 1996, Italy. Government of the People's Republic of Bangladesh.

3. Bangladesh Bureau of Statistics: Report on the Household Expenditure 1988/89. Ministry of Planning, Government of the People's Republic of Bangladesh, Dhaka, 1991.

4. Ministry of Health and Family Welfare: Bangladesh Country Paper. International Conference on Nutrition, 1992, Rome, Italy. Government of the People's Republic of Bangladesh, 1992.

5. UNICEF: The State of the World's Children. UNICEF, New York, 1998.

6. International Conference on Nutrition: World Declaration and Plan of Action for Nutrition. FAO \& WHO, Rome, 1992.

7. World Food Summit: Rome Declaration on World Food Security and World Food Summit and Plan of Action. FAO, Rome, 1996

8. Englyst HN, Kingman SM and Cummings JH : Classification and measurement of nutritionally important starch fractions. Eur. J Clin Nutr 1992;46 (Suppl 2):S33-S50.

9. Tetens I, Biswas SK, Glits $\emptyset$ LV, Kabir KA, Thilsted SH and Choudhury NH: Physico-chemical characteristics as indicators of starch availability from milled rice. J Cereal Sci 1997; 26:355-61.

10. Larsen HN, Christensen C, Rasmussen OW, Tetens I, Choudhury NH, Thilsted SH and Hermansen K: Influence of parboiling and physicochemical characteristics of rice on the glycemic index in non-insulin-dependent diabetic subjects. Eur J Clin Nutr 1996;50:22-7.

11. Choudhury NH, Biswas SK, Tetens I, Eggum BO: Protein quality evaluation of Bangladeshi modern rice varieties. 7 th Asian Congress of Nutrition, Beijing, China, October 7-11, 1995.

12. Choudhury NH, Biswas SK, Kabir KA, Tetens I, Thilsted SH, Graham R and the late Eggum BO: Nutritional quality of Bangladeshi rice varieties. 16th International Congress of Nutrition, Montréal, Canada, July 27-Aug 1, 1997.

13. Tetens I and Hassan N: Perception of rice varieties among rural people in Bangladesh. VII Bangladesh Nutrition Conference, Dhaka, March 15-17, 1997.

14. Thilsted SH, Roos N, Hassan N: The role of small indigenous fish species in food and nutrition security in Bangladesh. NAGA, The ICLAM Quarterly 1997; July-Dec $13-15$.

15. Hansen M, Thilsted SH, Sandström Kongsbak $\mathrm{K}$, Larsen $\mathrm{T}$, Jensen $\mathrm{M}$, and Sørensen SS Calcium absorption from small soft-boned fish $\mathrm{J}$ Trace Elem Med Biol (In press). 